\title{
"¡Nicas y mexicanos solidarios como hermanos!": el movimiento mexicano de solidaridad con Nicaragua (1974-1979)
}

\author{
"Nicaraguans and Mexicans in Solidarity \\ as Brothers!": The Mexican Solidarity \\ Movement with Nicaragua (1974-1979)
}

\author{
Gerardo Sánchez Nateras \\ (D) https://orcid.org/0000-0002-7115-4096 \\ El Colegio de México, México \\ gsanchez@colmex.mx
}

Resumen: Este trabajo abordará el movimiento mexicano de solidaridad con el pueblo de Nicaragua durante la insurrección sandinista (1977-1979), aportando elementos para el estudio de la historia transnacional de la revolución en Nicaragua y su impacto en la vida política mexicana. Se abordará el movimiento de solidaridad como un proceso heterogéneo dominado por tres actores fundamentales: el FSLN, el Estado mexicano y la izquierda política mexicana, cada uno intentando avanzar sus intereses particulares mediante la movilización política y el uso de la retórica de solidaridad. Se estudiarán algunos temas relacionados con la izquierda partidista y sindical en el contexto de la reforma política de 1977, el gobierno de José López Portillo y su política hacia el FSLN y la izquierda mexicana, así como los esfuerzos de propaganda y activismo del Sandinismo en México.

Cómo CITAR: Sánchez Nateras, G. (2020“¡Nicas y mexicanos solidarios como hermanos!”: el movimiento mexicano de solidaridad con Nicaragua (1974-1979). Secuencia (108), e1840. DoI: https://doi.org/10.18234/ secuencia.v0i108.1840 
Palabras clave: México; Nicaragua; FSLN; solidaridad; sandinista.

Abstract: This paper analyzes the Mexican solidarity movement with the Nicaraguan people during the Sandinista insurrection (1977-1979), providing elements for the study of the transnational history of the revolution in Nicaragua, and its impact on Mexican political life. It studies the solidarity movement as a heterogeneous process dominated by three key actors: the FSLN, the Mexican State and the Mexican political left, each trying to advance their interests through political mobilization and the use of solidarity discourse. Certain issues related to the partisan and trade union left will be studied in the context of the 1977 political reform, the government of José López Portillo and its policy towards the FSLN and the Mexican left, as well as the propaganda and activism efforts of Sandinismo in Mexico.

Key words: Mexico; Nicaragua; FSLN; solidarity; sandinista.

Recibido: 9 de marzo de 2020 Aceptado: 30 de julio de 2020

Publicado: 08 de enero de 2021

Una bala para Somoza. Apoya moralmente. Apoya económicamente. Una bala le cuesta al FSNL 25\$. Tal vez tu bala le pegue a Somoza. ${ }^{1}$

$\mathrm{E}$ ste artículo presentará una visión panorámica sobre el movimiento mexicano de solidaridad con Nicaragua entre 1977 y 1979. Durante este periodo, México se convirtió en uno de los principales escenarios de los procesos de solidaridad con la lucha del Frente Sandinista de Liberación Nacional (FSLN) y uno de los ejes más importantes de las actividades políticas y de propaganda realizadas por este grupo guerrillero. ${ }^{2}$

1 "Una bala para Somoza", volante del Comité de Solidaridad con Nicaragua, $\mathrm{CCH}-\mathrm{Va}-$ llejo, 1979. Archivo personal de Francisco Navarro. Se agradece la ayuda de Francisco Navarro y Efraín Navarro por prestar su valioso archivo personal para esta investigación.

${ }^{2}$ Como se verá posteriormente, el número de organizaciones de solidaridad en México fue comparativamente mayor al de otros países de América Latina y alrededor del mismo ta- 
En términos más amplios, este trabajo busca mostrar cómo el proceso revolucionario en Nicaragua influyó en el escenario político mexicano en el contexto de una limitada, pero importante, apertura política durante el gobierno de José López Portillo. También buscará mostrar las formas de interacción (real y simbólica) de la izquierda mexicana con las luchas antiimperialistas a finales de los años setenta, sus mecanismos de organización, y su papel destacado en el movimiento de solidaridad. El artículo expondrá cómo el movimiento de solidaridad tuvo un carácter heterogéneo, dominado por tres ejes principales: el FSLN y sus aliados, los grupos de izquierda no armada, y el gobierno mexicano. Como se verá más adelante, la interacción entre estos tres actores y sus intereses políticos le dieron forma al movimiento mexicano de solidaridad con Nicaragua.

En los últimos años varios jóvenes investigadores se han abocado al estudio de los movimientos de solidaridad con Nicaragua, abordando las conexiones entre el FSLN y los grupos de solidaridad de Europa occidental y Estados Unidos (Agreda y Helm, 2016; Apelt 2015; Christiaens, 2014; Perla, 2009; Van Ommen, 2016). En América Latina, una de las áreas más importantes para las labores de solidaridad del FSLN, tenemos pocos trabajos que nos permitan explorar estos temas y abordar la solidaridad desde una perspectiva "sur-sur" (Hatzky y Stites Mor, 2014, p. 131). ${ }^{3}$ A pesar de que este no es un trabajo comparativo, mostraremos algunas importantes diferencias y coincidencias entre los esfuerzos de solidaridad en México y en otros países.

Existen pocos trabajos que hayan abordado el papel de la solidaridad mexicana con Nicaragua (Yanes Rizo, 2018). A pesar de esto, contamos con varios trabajos sobre la política exterior de México hacia América Central que presentan algunos detalles importantes y amplios elementos para enriquecer el análisis (Herrera León, 2011; Ojeda, 1985; Toussaint, Rodríguez de Ita, Vázquez, 2001; Toussaint, 2013; Vázquez y Campos, 2016, entre otros). ${ }^{4}$ De forma más específica, contamos con trabajos sobre el papel de los medios durante la insurrección en Nicaragua (Morales Flores, 2016), sobre la diplomacia del FSLN (Campos, 2012) y sobre el papel de los grupos guerrilleros salvadoreños

maño que el de Alemania, uno de los principales centros de actividad de solidaridad con 150 comités (Cardenal, 2004, p. 47).

${ }^{3}$ Por ejemplo, los trabajos de Paula Fernández Hellmund (2013) y trabajos testimoniales como los de José Picado Lagos (2013) y Ema Yanes Rizo (2018).

${ }^{4}$ La bibliografía sobre México y el conflicto centroamericano es amplia, las obras citadas sólo pretenden ser una breve aproximación de la literatura más reciente sobre el tema. 
y guatemaltecos en México (Pirker y Núñez Rodríguez, 2016; Campos, 2016; Valdez Gordillo, 2016; Vázquez y Campos, 2019; Pérez, 2020).

Este artículo presentará un esbozo de las diversas fases del movimiento mexicano de solidaridad con Nicaragua. Posteriormente, abordará el periodo que va de 1977 a 1979, momento de gran efusión y movilización popular por el auge del FSLN. Se mostrará el rápido desarrollo del movimiento de solidaridad, el papel de la protesta doméstica dentro de este y, finalmente, la convergencia y el uso del movimiento de solidaridad por parte del Estado mexicano que intentó utilizar las "formas" de la solidaridad para ocultar su apoyo directo al FSLN. ${ }^{5}$

\section{LOS ORÍGENES DEL MOVIMIENTO DE SOLIDARIDAD EN MÉXICO}

A diferencia de los grupos de solidaridad que surgieron en Europa durante los años setenta del siglo xx, los esfuerzos de solidaridad en México tuvieron una larga historia que comenzó con los esfuerzos diplomáticos de Augusto César Sandino durante los años treinta. La larga estadía de Sandino en México, y su retorno a final de los años treinta, en busca de apoyo por parte del incipiente gobierno revolucionario de Emilio Portes Gil y Plutarco Elías Calles, sentaron las bases de una identificación fuerte entre la lucha por la liberación en América Central y el gobierno revolucionario de México (Carr, 2014; Jeifets y Jeifets, 2017).

Tras la derrota de Sandino, el movimiento de solidaridad en México entró en una segunda etapa y se mantuvo vivo mediante los esfuerzos de grupos de exiliados nicaragüenses radicados en México. Durante los años cuarenta la colonia de nicaragüenses en México se convirtió en el principal vehículo de las campañas en contra del régimen dictatorial en Nicaragua. ${ }^{6}$ Es

${ }^{5}$ Este trabajo no retoma el concepto de "diplomacia guerrillera" como ha sido elaborada en los trabajos de Brigham (1998) sobre e NLF de Vietnam, y Connelly (2002) para Algeria, ya que más que un seguimiento a las labores del FSLN en México se busca destacar cómo las labores de propaganda del FSLN fueron recibidas y utilizadas por parte de algunos sectores de la sociedad y el gobierno de México. Para el FsLn, algunos autores como Fabián Campos, Kim Christiaens y Eline Van Ommen han trabajado el tema de la diplomacia sandinista (Campos, 2012; Christiaens, 2014; Van Ommen, 2020).

${ }^{6}$ Para una aproximación a las actividades del exilio nicaragüense, véanse los trabajos importantes de Laura Moreno (2015). 
importante constatar que, como señala el historiador Kim Christiaens (2014, pp. 616-621), tanto en Europa como en México las comunidades de exiliados formaron la base de los esfuerzos de solidaridad y desempeñaron un papel fundamental en la creación de los comités de solidaridad posteriores.

El movimiento de solidaridad contra Somoza inició una tercera etapa durante los años sesenta, bajo el influjo de la guerra fría e inspirado por el ejemplo de la revolución cubana (Altamirano, 2000). La cercanía entre el movimiento comunista mexicano e internacional con el exilio nicaragüense y el incipiente grupo organizador del Frente Revolucionario Sandino (antecesor del FSLN) alimentaron las sospechas del gobierno, ansioso por una posible “infiltración” comunista en el país. De acuerdo con informes de la Dirección Federal de Seguridad (DFs), en 1971 Bayardo Altamirano (quien Carlos Fonseca señalaría como uno de los principales cuadros de la organización), fue arrestado para ser interrogado por sus actividades de "tipo subversivas". El documento de la DFs señala que desde 1959, él y varios nicaragüenses residentes en México se comenzaron a organizar en casas particulares, especialmente en el domicilio de Edelberto Torres, un destacado académico guatemalteco, y de Concepción Palacios (médico nicaragüense quien había colaborado con Sandino durante los años treinta). A principio de los años sesenta más de 40 nicaragüenses decidieron conformar un grupo guerrillero y trasladarse a Nicaragua para combatir en contra de Somoza, lo que posteriormente sería llamado el Frente Revolucionario Sandino, antecesor del FSLN. ${ }^{7}$ Tras el colapso de este esfuerzo guerrillero, Bayardo Altamirano regresó a México para continuar con sus estudios, pero mantuvo contacto con los grupos clandestinos nicaragüenses y con la colonia de exiliados de aquel país, quienes apoyaban con fondos para el FSLN. La situación del grupo era poco alentadora y sus esfuerzos eran apoyados por la venta de libros autoeditados tales como Radiografía de un país: Nicaragua.

De acuerdo con los documentos de la DFs, Concepción Palacios y Óscar Turcios, un militante del FSLN, eran los principales contactos de la organización en México. Ellos estaban encargados de recaudar fondos, trasladar armas provenientes de Estados Unidos, alojar a guerrilleros y establecer con-

${ }^{7}$ Elementos subversivos del Frene Sandinista de Nicaragua que operan en México, 12 de agosto de 1971. Frente Sandinista de Liberación Nacional, Nicaragua, y/o Comité de Solidaridad con Nicaragua. Fondo Gobernación. Dirección Federal de Seguridad. Caja 276, leg. 1. Archivo General de la Nación (en adelante AGN), México. Bayardo Altamirano (2000) relata parte de su trabajo coordinando acciones de solidaridad. 
tactos con nicaragüenses clandestinos en México. ${ }^{8}$ A pesar del acoso y la vigilancia de las fuerzas de seguridad de México, el FSLN extendió sus esfuerzos en el país, estableciendo, incluso, un regional de México que servía como base para las acciones de propaganda, descanso y tránsito de militantes sandinistas. Las actividades de los grupos sandinistas en México durante este periodo podían ser caracterizadas por tres elementos, 1) estaban circunscritas a los grupos exiliados nicaragüenses, 2) en su mayoría eran de carácter clandestino y estaban encaminadas a apoyar materialmente a la lucha en Nicaragua, y 3 ) sufrían del acoso y vigilancia por las fuerzas de seguridad del Estado. ${ }^{9}$

La cuarta etapa del movimiento de solidaridad en México emergió a la par de una evolución teórica de los movimientos radicales latinoamericanos que lentamente se fueron apartando de la ortodoxia de las tesis ligadas a la idea del foco guerrillero y la ortodoxia revolucionaria cubana (Marchesi, 2017, p. 23). Entre 1974 y 1976, una serie de fracasos del FSLN por iniciar un foco guerrillero en las montañas y zonas rurales de Nicaragua llevaron a que esta organización se replanteara sus formas de lucha, dando cada vez más importancia a factores políticos y diplomáticos del proceso armado (Ortega, 2004, pp. 264265). El entusiasmo generado por el gobierno de Salvador Allende y el importante desarrollo de grupos de solidaridad con Chile y Vietnam entre 1972 y 1974, mostraron las posibilidades de la movilización política internacional para el FSLN en un momento de redefinición política y militar (Christiaens, 2018).

Estas transformaciones políticas se vieron reflejadas en el movimiento de solidaridad con Nicaragua en México, que se nutrió además de una larga tradición de apoyo al Sandinismo. De acuerdo con el testimonio de la poeta mexicana Thelma Nava, en una entrevista realizada por Emma Yanes Rizo, en 1974 fue reclutada por el escritor nicaragüense militante del FsLN, Francisco de Asís, para organizar un comité de solidaridad que le pudiera dar legitimidad internacional a las acciones del FSLN que se avecinaban en Nicaragua. De forma apresurada se planearon varias actividades de solidaridad en Mé-

${ }^{8}$ Elementos subversivos del Frene Sandinista de Nicaragua que operan en México, 12 de agosto de 1971. Frente Sandinista de Liberación Nacional, Nicaragua, y/o Comité de Solidaridad con Nicaragua. Fondo Gobernación. Dirección Federal de Seguridad. Caja 27, leg. 1 (versión pública). AGN, México.

${ }^{9}$ El interrogatorio de Bayardo Altamirano era sólo un ejemplo de los esfuerzos del gobierno mexicano para limitar la presencia sandinista en el país y evitar el contacto entre la izquierda mexicana y los militantes nicaragüenses. Otras organizaciones guerrilleas y grupos de exiliados de diversas nacionalidades también sufrieron el acoso y la vigilancia de las fuerzas de seguridad del estado (Campos, 2016; Yankelevich, 2019). 
xico, "Por primera vez vino Carlos Mejía Godoy a México. Se hizo un festival de poesía en el local del CLETA" (Yanes Rizo, 2018, pp. 81-82). Estos primeros esfuerzos fueron financiados por algunas organizaciones como el Sindicato de Trabajadores de la Universidad Nacional Autónoma de México (stunam) y algunos destacados miembros de la colonia de nicaragüenses, tales como la veterana militante Concepción Palacios.

Después de esta primera jornada de solidaridad, se decidió conformar de forma permanente un Comité Mexicano de Solidaridad con el pueblo de Nicaragua. Con el impulso de Thelma Nava y bajo la coordinación del fsLN se decidió que este grupo estaría conformado por intelectuales destacados, entre ellos el diputado federal por el Partido Revolucionario Institucional (PRI), Carlos Pellicer, quienes fundaron el Comité Mexicano de Solidaridad a finales de 1974. Este primer Comité se encontraba en contacto permanente con el FSLN, bajo la dirección del entonces responsable en México, Ramiro Contreras. En 1975, Thelma Nava viajó a Cuba donde se reunió con los dirigentes sandinistas Benito Escobar, Humberto Ortega y Daniel Ortega para coordinar actividades (Yanes Rizo, 2018, p. 23). Es notable que, a diferencia de otros movimientos de solidaridad, en México el comité de solidaridad con Nicaragua fue creado varios años antes que en otros países como Argentina, Alemania o España (Fernández Hellmund, 2013; Agreda Portero y Helm, 2016 p. 7).

Entre 1974 y 1977 el Comité de Solidaridad llevó a cabo un gran número de actividades de protesta y culturales, organizando festivales en la Casa del Lago de Chapultepec, eventos en el Auditorio de la Facultad de Ciencias, Medicina, y Filosofía y Letras de la UNAM, así como conciertos en algunos barrios populares como el Pedregal de Santo Domingo con "canciones de protesta y teatro", y la participación de Judith Reyes y Carlos Mejía Godoy. ${ }^{10}$ El grupo de solidaridad publicó en un primer momento un boletín llamado Vanguardia y posteriormente la Gaceta Sandinista (Yanes Rizo, 2018, p. 84). A finales de 1976 organizó un evento con más de 300 personas para conmemorar la muerte de los dirigentes Sandinistas Carlos Fonseca y Eduardo Contreras, quienes habían sido asesinados por la Guardia Nacional de Nicaragua. ${ }^{11}$

${ }^{10}$ Informe sobre actividades de protesta en la Ciudad de México para el General de División Diplomado de Estado Mayor Hermenegildo Cuenca Díaz, Secretaría de la Defensa Nacional, 1974. Archivos de la Represión, México. Recuperado de https://biblioteca.archivosdelarepresion.org/s/comverdad/item $/ 54087 \# ? \mathrm{c}=\& \mathrm{~m}=\& \mathrm{~s}=\& \mathrm{cv}=\& \mathrm{xywh}=1421 \% 2 \mathrm{C} 1375 \% 2 \mathrm{C} 3166 \% 2 \mathrm{C} 1981$

${ }^{11}$ Jornada de Solidaridad con el pueblo de Nicaragua, 23 de noviembre de 1976. Fondo Gobernación. Dirección Federal de Seguridad. Caja AC 229/4223, exp. 11-56, leg. 3. AGN, México. 
La división del FSLN repercutió en el Comité de Solidaridad, Thelma Nava señala que el Comité Mexicano continuó operando en coordinación con la facción tercerista, bajo la dirección de Ramiro Contreras. ${ }^{12}$ En 1976 el Comité de Solidaridad apoyó para difundir las denuncias públicas orquestadas por los terceristas en contra del régimen de Somoza, que fueron utilizadas por el Congreso estadunidense para justificar el fin de los programas de ayuda militar al gobierno de Nicaragua (Yanes Rizo, 2018, pp. 126-127).

\section{LA INSURRECCIÓN EN NICARAGUA Y EL MOVIMIENTO DE SOLIDARIDAD}

El declive del somocismo y el aumento de los conflictos políticos y sociales en Nicaragua coincidió en México con la reforma política de 1977. Para final de los años setenta el régimen Priista se encontraba envuelto en una fuerte crisis política y social resultado de años de abusos por parte de las fuerzas de seguridad el Estado, los estrechos límites de participación política y la crisis del modelo económico. La reforma política iniciada por el gobierno de José López Portillo buscó abrir, de forma limitada, el restringido campo político electoral a nuevos actores. Permitió el registro de nuevos partidos y la difusión de sus campañas de oposición en los medios de comunicación, así como permitir una mayor presencia de la oposición en el poder legislativo (Rodríguez Kuri y González Mello, 2008, pp. 734-735). La reforma también era un intento del gobierno mexicano por limitar la radicalización de las organizaciones de izquierda en el país en el contexto de la guerra sucia (1965-1985). Esta nueva iniciativa, que también había sido producto de la presión de los partidos de izquierda clandestinos y sindicatos independientes, permitió un aumento considerable de la actividad política de los grupos de izquierda (Gaxiola, 2018; Fernández, 1978). Este clima de reforma favoreció las actividades de solidaridad que ya se venían desarrollando en México desde 1974.

12 Tras la muerte de Carlos Fonseca, el FSLN quedó dividido en tres facciones separadas a grandes rasgos por diferencias ideológicas. La Tendencia Proletaria que buscaba la creación de un partido de vanguardia más cercano a la ortodoxia marxista; la facción Guerra Popular Prolongada, que enfatizaba la creación de una base guerrillera en las montañas de Nicaragua; y la facción Tercerista o insurreccional que se enfocaba más en la creación de alianzas amplias y acciones políticas y de propaganda para fomentar una insurrección nacional. En marzo de 1979 las tres tendencias se unificaron nuevamente. 
A finales de 1977 la situación en Nicaragua comenzó a deteriorarse de forma súbita a medida que aumentó la oposición de las clases medias y los grupos empresariales. En octubre de 1977 la facción tercerista del FSLN llevó a cabo una serie de ataques coordinados por toda Nicaragua que recibieron una amplia cobertura mediática. Siguiendo la misma estrategia política desarrollada desde 1974, el Comité Mexicano de Solidaridad buscó dar eco a los esfuerzos armados del FSLN, lanzando un llamado público a "todas las fuerzas democráticas de México, partidos políticos, organizaciones, sindicatos, intelectuales, estudiantes y al pueblo en general" a manifestar su rechazo al régimen somocista y a apoyar a la "vanguardia del pueblo nicaragüense", el FSLN ${ }^{13}$ La respuesta de las organizaciones de izquierda fue sustancial. El día siguiente del llamado del Comité de Solidaridad varias organizaciones de izquierda realizaron una concentración afuera de la embajada de Nicaragua ${ }^{14} \mathrm{El}$ día 30 de octubre todos los partidos socialistas y comunistas en México secundaron los esfuerzos del Comité y organizaron un evento de protesta en el Cine Versalles al que asistieron alrededor de 400 personas de entre los cuales alrededor de la mitad eran extranjeros, principalmente nicaragüenses y chilenos. ${ }^{15}$

La confluencia entre los esfuerzos del FSLN, el Comité de Solidaridad y la izquierda partidista en México inauguró una quinta etapa del movimiento de solidaridad en México. Desde los primeros meses de 1978 los diferentes partidos políticos de izquierda tomaron un gran interés por la situación en Nicaragua. El Partido Comunista Mexicano, Partido Socialista de los Trabajadores, Partido Mexicano de los Trabajadores, Partido Popular Socialista, el Partido Revolucionario de los Trabajadores, y sus diversas organizaciones afines, comenzaron a coordinar acciones con el Comité Mexicano de Solidaridad para dar un gran impulso a la causa del FsLN en el país. Aprovechando la apertura limitada de la reforma política para posicionarse con más fuerza en la esfera pública. Como se verá más adelante, la mayoría de las organizaciones que realizaron actividades de solidaridad estaban relacionadas con los sindi-

${ }^{13}$ Llamamiento del Comité Mexicano de Solidaridad con el Pueblo de Nicaragua, 19 de octubre de 1979. Fondo Gobernación. Dirección Federal de Seguridad. Caja AC 229/4223, exp. 11-56, leg. 4. AGN, México.

${ }^{14}$ Comité Mexicano de Solidaridad con el pueblo de Nicaragua, 20 de octubre de 1977. Fondo Gobernación. Dirección Federal de Seguridad. Caja AC 229/4223, exp. 11-56, leg. 4. AGN, México.

${ }^{15}$ Acto de solidaridad con el pueblo de Nicaragua, 30 de octubre de 1977. Fondo Gobernación. Dirección Federal de Seguridad. Caja AC 229/4223, exp. 11-56, leg. 4. AGN, México. 
catos y partidos políticos de izquierda. En España, el movimiento de solidaridad siguió un proceso similar, apoyado por los partidos de izquierda en medio de un proceso de transición democrática (Agreda Portero y Helm, 2016, p. 10).

El lazo entre el movimiento de solidaridad y la nueva reforma política fue tan importante que, en mayo de 1978, cuando el Partido Comunista Mexicano dejó la militancia clandestina, organizó un festival en el Palacio de los Deportes de la Ciudad de México en el que se realizó una amplia campaña de solidaridad a favor del FSLN, contando con la presencia de Carlos Mejía Godoy y los de Palacagüina. En ese evento, Efraín Huerta, uno de los principales organizadores del Comité de Solidaridad, fue homenajeado por el PCM. ${ }^{16}$

Los esfuerzos de solidaridad recibieron también el apoyo de otros grupos y movimientos latinoamericanos radicados en México. Uno de ellos fue la Casa de Chile, creada por algunos exiliados del golpe de Estado de 1973 en contra de Salvador Allende. Los chilenos exiliados ayudaron a organizar colectas de dinero, ropa, calzado, medicamento y plasma para ayudar al pueblo de Nicaragua. En febrero de 1978, la Casa de Chile organizó un acto de solidaridad conmemorando los 44 años de la muerte de Sandino. ${ }^{17} \mathrm{Al}$ igual que con los movimientos de solidaridad en Europa, el antecedente del movimiento de solidaridad con Chile fue una de las bases de los esfuerzos de solidaridad con Nicaragua en México (Christiaens, 2018).

También existían factores externos que posiblemente hayan impulsado aún más el apoyo de los partidos de izquierda con el FSLN y el movimiento de solidaridad. A finales de julio de 1978, una gran delegación de militantes comunistas y socialistas viajaron al XI Festival Mundial de la Juventud en La Habana. De acuerdo con documentos del Departamento de Estado, esta ocasión fue aprovechada por Fidel Castro para anunciar, en privado, la unificación de las tres tendencias del FSLN y para pedir que los presentes (partidos políticos y grupos guerrilleros) demostraran su solidaridad internacionalista colaborando con el FSLN. ${ }^{18}$ De acuerdo con reportes de

${ }^{16}$ Gaceta Sandinista, año 3, núm. 2, p. 18. Archivo del Instituto de Historia Nicaragua y Centroamérica (en adelante AIHNC, Nicaragua.

17 XLIV aniversario del asesinato de Augusto César Sandino, 23 de febrero de 1978. Fondo Gobernación. Dirección Federal de Seguridad. Caja AC 229/4223, exp. 11-56, leg. 4, f. 131. AGN, México.

${ }^{18}$ Cuba's Renewed Support for Violence in Latin America. United States Department of State. Bureau of Public Affairs. December 14, 1981, p. 6. CIA-RDP84B00049R001800100003-4. Declassified Documents CIA FOIA. 
inteligencia de la DFs, en Cuba, el oficial político de la embajada cubana en México, Jorge Luis Joa, miembro del Departamento América del Partido Comunista Cubano, participó en por lo menos tres reuniones "concernientes a Nicaragua" junto con otros altos funcionarios cubanos como Leonel Soto Prieto y Manuel Piñeiro, el conocido director del Departamento América del Partido Comunista Cubano. ${ }^{19}$

El movimiento de solidaridad también permitió vincular (real o discursivamente) las luchas de la izquierda mexicana con el progreso del proyecto comunista y socialista global y la lucha en contra del imperialismo. El espíritu internacionalista de algunos sectores del movimiento se veía reflejado en sus volantes y consignas, por ejemplo, el Comité Permanente de Solidaridad del ccr Vallejo repartió un panfleto a finales de 1978 en el que se leía: "el imperialismo yanqui se tambalea, por la lucha en Vietnam, Irán, y ahora Nicaragua, lucha que también es parte del avance de la revolución proletaria a nivel mundial". ${ }^{20} \mathrm{Al}$ participar activamente en la liberación de Nicaragua, los grupos de izquierda mexicanos también buscaron formar parte de un proceso global y continental opuesto al colonialismo y la exploración imperialista. A principios de octubre de 1978, durante uno de los eventos de solidaridad más grandes realizado en el Auditorio Nacional, el maestro de ceremonias declaró que los presentes deberían reafirmar su "decisión de continuar con la lucha hasta la victoria final de los pueblos de toda América" ${ }^{21}$

Los partidos de oposición de corte socialista y comunista redoblaron sus esfuerzos de solidaridad movilizando activistas en sindicatos, universidades y colonias populares para apoyar al pueblo de Nicaragua. De acuerdo con una base de datos elaborada a partir de reportes de vigilancia de la Dirección Federal de Seguridad entre 1978 y 1979, los diversos partidos de izquierda fueron el centro articulador de los esfuerzos de solidaridad en el Distrito Federal

19 "Sin título", Comité de Solidaridad. Fondo Gobernación. Dirección Federal de Seguridad. Caja 176, leg. 3, f. 146, s. f. AGN, México.

20 "A la comunidad de Vallejo". Comité Permanente de Vallejo, C. 25-29 de junio 1979. Archivo personal de Francisco Navarro, México.

${ }^{21}$ Comité Nacional de apoyo al Frente Sandinista de Liberación Nacional. Fondo Gobernación. Dirección Federal de Seguridad. Comité de Solidaridad. Caja 276, leg. 2, f. 144. AGN, México. Para una visión general de este proceso de transnacionalización de las luchas locales, véase Hatzky y Stites Mor (2014). 
y los estados, participando en la organización de comités de solidaridad y actividades en Sinaloa, Puebla, Nuevo León, Michoacán y Jalisco. ${ }^{22}$

Tras la espectacular toma del Palacio Nacional en Nicaragua y la insurrección de septiembre, el movimiento de solidaridad cobró fuerza debido a la cobertura mediática (con frecuencia exagerada) de las acciones del FSLN. La estructura de solidaridad permitía, además amplificar estas noticias. ${ }^{23} \mathrm{De}$ acuerdo con la base de datos elaborada a partir de reportes de la DFs, entre septiembre de 1978 y julio de 1979 más de 100 grupos y organizaciones se sumaron a las actividades de solidaridad en todo México principalmente en escuelas y universidades. Este proceso concuerda con las mismas conclusiones que Van Ommen (2016, p. 8) sugirió en sus investigaciones sobre el movimiento de solidaridad en Holanda: en particular la importancia de las acciones militares del FSLN para fortalecer el movimiento de solidaridad.

Los estudiantes de las escuelas públicas se convirtieron en los principales promotores del movimiento de solidaridad con Nicaragua creando pequeños comités de solidaridad. Estos comités se dieron a la tarea de repartir volantes, informar sobre lo que estaba sucediendo en Nicaragua y recabar fondos para la lucha en Nicaragua; organizaron exposiciones fotográficas, realizaron pintas y pegaron carteles. Largometrajes y cortometrajes también fueron utilizados con frecuencia para difundir propaganda del FSLN. De acuerdo con reportes de la DFs, las películas del FSLN eran particularmente populares y juntaban a cientos de estudiantes. Algunas películas como Patria o Muerte, La consigna y Septiembre de 1978, presentaban el reclutamiento de guerrilleros Sandinistas y escenas de combates en contra de la dictadura somocista. ${ }^{24}$

El movimiento de solidaridad en México no fue un fenómeno limitado a la Ciudad de México. En los estados de la república la causa sandinista tuvo un fuerte respaldo. El 28 de septiembre, en la Universidad Juárez de Durango, un representante del fSLN, Alejandro Arce, organizador del Comité Estatal por la Paz y Miembro del Conejo Mundial por la Paz, habló ante al menos

${ }^{22}$ Esta base de datos fue elaborada a partir de la información proveniente del expediente del Fondo Gobernación. Dirección Federal de Seguridad. Comité de Solidaridad. Legs. 2, 3 y 4. AGN, México.

${ }^{23}$ Para un trabajo detallado sobre la cobertura mediática de la insurrección, véanse los trabajos de Mónica Morales.

${ }^{24}$ Escuela Normal Superior. Fondo Gobernación. Dirección Federal de Seguridad. Comité de Solidaridad. Caja 276, leg. 3, f. 178; Instituto Politécnico Nacional. 28 de marzo de 1979. Fondo Gobernación. Dirección Federal de Seguridad. Comité de Solidaridad. Caja 276, leg. 3, f. 27. AGN, México. 
1000 personas "en su mayoría de origen humilde, procedentes de colonias proletarias" convocando a una manifestación en la plaza de armas a favor del pueblo de Nicaragua. El día siguiente, más de 400 personas asistieron el evento en donde, además de llamar a la solidaridad con el pueblo de Nicaragua, algunos oradores como el catedrático de la Universidad Juárez, Luis Ángel Martínez Díaz, hablaron sobre la necesidad de que en México "se implante el socialismo" mediante la unificación de las agrupaciones de izquierda. Posteriormente, el grupo recorrió varias calles del centro de Durango portando una bandera de Nicaragua con la frase "México y Nicaragua hacia el Socialismo", para regresar a la Plaza de Armas en donde quemaron la bandera de Estados Unidos. ${ }^{25}$ Algunos grupos políticos de oposición aprovecharon para repartir volantes recordando la masacre de Tlatelolco y "la violenta represión estudiantil". A finales de septiembre, el periódico El Sol de Durango publicó una carta abierta al presidente López Portillo en la que se condenaba los acontecimientos y se solidarizaba con aquel país. ${ }^{26}$

En la Universidad Autónoma del Estado de México, uno de los organizadores del Comité de Solidaridad con el Pueblo de Nicaragua, Roberto Andrés Guizar Guarneros, declaró que, en el Estado de México, "[están] conscientes de la necesidad del internacionalismo proletario en la lucha hacia el Socialismo, en la inteligencia de que Nicaragua integra una vanguardia antimperialista y proletaria" y que por esta razón las diferentes organizaciones del Estado de México apoyaban la lucha en Nicaragua. Añadió, además, que los movimientos sindicales en México eran "similares a los movimientos democráticos que actualmente se están llevando a cabo en Nicaragua". ${ }^{27}$

En Puebla, estudiantes de la Escuela de Medicina de esa ciudad realizaron asambleas de solidaridad con el pueblo de Nicaragua con la asistencia de al menos 60 personas. Durante estos eventos se acordó integrar brigadas para

${ }^{25}$ Sin título. Fondo Gobernación. Dirección Federal de Seguridad. Comité de Solidaridad con el Pueblo de Nicaragua. Leg. 2, f. 198. AGN, México.

${ }^{26}$ Sin título. Fondo Gobernación. Dirección Federal de Seguridad. Comité de Solidaridad con el Pueblo de Nicaragua. Leg. 2, f. 200. AGN, México. La carta fue firmada por el Comité Estatal por la Paz integrado por el Sindicato de Trabajadores y Empleados de la Universidad Juárez de Durango, las colonias "proletarias" Emiliano Zapata, Lucio Cabañas, y Asentamientos Humanos, PCM y PPM, Frente de Fincas Urbanas, Maestros Democráticos de la UJED, Coalición Ferrocarrilera, Frente Universitario Independiente, SUTERM y MRM.

${ }^{27}$ Estado de México. Fondo Gobernación. Dirección Federal de Seguridad. Comité de Solidaridad con el Pueblo de Nicaragua. Caja 276, leg. 2, foja 211. AGN, México. 
visitar consultorios de esa localidad para recolectar medicinas, víveres y ropa, para enviarlos al Comité de Solidaridad localizado en el Distrito Federal. ${ }^{28}$

En Morelos, los esfuerzos de solidaridad se encontraban agrupados alrededor de la diócesis de Cuernavaca, a cargo del famoso obispo de la ciudad Sergio Méndez Arceo, quien era conocido por su política de izquierda inspirada por la teología de la liberación. En Morelos, la red de solidaridad estaba conformada por jóvenes comunistas, figuras religiosas, periódicos de izquierda como el Correo del Sur, y otras organizaciones de la sociedad civil como la Cooperativa de Consumo del Valle de Cuernavaca y el Colegio Tlahuica. Los grupos en Morelos organizaron tres torneos de ajedrez con el campeón nacional Marcel Sisniega para recabar fondos para Nicaragua. ${ }^{29}$

En otros estados, donde los grupos comunistas y socialistas eran menos numerosos, no se conformó un Comité de Solidaridad con el pueblo de Nicaragua. Tal fue el caso de Guanajuato que para octubre de 1978 todavía no contaba con una representación permanente del movimiento. ${ }^{30}$ En Aguascalientes tampoco se organizó un Comité de Apoyo al FSLN, aunque sí se realizaron algunas actividades de asilados políticos nicaragüenses. ${ }^{31}$ En Veracruz, el Comité de Solidaridad de aquel estado se conformó hasta mediados de junio de 1979.

Como mostraba el ejemplo de Morelos, Estado de México y Durango, los esfuerzos de solidaridad se agrupaban en torno a grupos y organizaciones particulares que podían coordinar los esfuerzos de solidaridad locales debido a su capacidad de movilización, su legitimidad y sus recursos políticos y económicos. En Morelos, el movimiento de solidaridad utilizaba vínculos preexistentes y los lazos entre religiosos para enviar ayuda para la lucha en Nicaragua sin pasar por los canales controlados por el FSLN. Como había declarado el propio Méndez Arceo, él recibía ayuda de "diferentes instituciones de auxilio de Estados Unidos de Norteamérica, Canadá y Europa, para el pueblo de Nicaragua", que a su vez remitía al arzobispado de Nicaragua

${ }^{28}$ Estado de Puebla. Fondo Gobernación. Dirección Federal de Seguridad. Comité de Solidaridad con el pueblo de Nicaragua. Caja 276. AGN, México.

${ }^{29}$ Sin título. Fondo Gobernación. Dirección General de Investigaciones Políticas y Sociales. Caja 1508C, exp. 10, foja 79. AGn, México.

${ }^{30}$ Estado de Guanajuato. Fondo Gobernación. Dirección Federal de Seguridad. Comité de Solidaridad con el pueblo de Nicaragua. Leg. 2, f. 219. Agn, México.

${ }^{31}$ Actividades de asilados políticos nicaragüenses. Fondo Gobernación. Dirección Federal de Seguridad. Comité de Solidaridad con el pueblo de Nicaragua. Leg. 3, f. 125, 14 de mayo de 1979. AGN, México. 
controlado por monseñor Obando y Bravo. ${ }^{32}$ En cambio, en el Estado de México, el movimiento de solidaridad estaba más dominado por los sindicatos y los partidos políticos locales.

Las dispares condiciones de cada uno de los grupos que conformaban la red informal del movimiento de solidaridad en México determinaron que las acciones de solidaridad tuvieran un carácter multiclasista. De la misma forma que los militantes sandinistas se podían presentar en el Palacio de Bellas Artes y en el Auditorio Nacional, también era común que asistieran a pequeños eventos en localidades marginadas y colonias populares. Algunos comités organizaron eventos en colonias recién fundadas como la colonia Tierra y Libertad de Ciudad Juárez, en Ciudad Nezahualcóyotl, y otras áreas de las periferias metropolitanas. ${ }^{33}$ De esta manera, los militantes del FSLN actuaron dentro de los marcos creados por las necesidades e intereses de los diferentes movimientos de solidaridad locales.

\section{LA CREACIÓN DEL COMITÉ COORDINADOR NACIONAL Y LOS ESFUERZOS DEL FSLN}

La explosión de actividades de solidaridad por todo el país empujó a la creación de un Comité Coordinador a nivel nacional para encauzar las dispares actividades que se venían realizado de forma independiente. De acuerdo con documentos de la DFS, desde mediados de septiembre de 1978, el Comité Mexicano de Solidaridad entabló pláticas con los diversos partidos de izquierda en el país para crear una "oficina de coordinación de solidaridad con Nicaragua". Los informes de inteligencia mexicanos también señalan que estos esfuerzos contaron con el respaldo de Jorge Luis Joa, oficial del Departamento América, director de las actividades de inteligencia de Cuba en México y de Francisco de Asís, encargado de coordinar las actividades de solidaridad por parte del FSLN. ${ }^{34}$ Esta confluencia de actores mostraban la diversidad de

32 Estado de Morelos. Fondo Gobernación. Dirección Federal de Seguridad. Comité de Solidaridad con el pueblo de Nicaragua. Leg. 3, f. 189, 10 de junio de 1979. AGN, México.

${ }^{33}$ Estado de México. Fondo Gobernación. Dirección Federal de Seguridad. Comité de Solidaridad. Caja 276, leg. 2, f. 166, 30 de noviembre de 1978; Leg. 2, f. 242, 17 y 18 de octubre de 1978; f. 55, 10 de noviembre de 1978. AGN, México.

${ }^{34}$ Comité de Solidaridad, s. f. Fondo Gobernación. Dirección Federal de Seguridad. Caja 276, leg. 3, f. 146. AGN, México. 
intereses que dieron forma al movimiento de solidaridad, así como su creciente importancia política.

Las reuniones de coordinación rindieron fruto el 26 de septiembre de 1978 con la creación del Comité Coordinador, instalado en las oficinas del Comité Mexicano de Solidaridad con el Pueblo de Nicaragua. A la primera reunión general de la organización asistieron alrededor de 75 personas "representantes de organizaciones sociales, obreras, políticas y partidos de izquierda". La junta fue presidida por Natalio Vázquez Pallares (un destacado abogado y político michoacano de ideología socialista quien se había desempeñado como oficial mayor de la Confederación Nacional Campesina, rector de la Universidad de San Nicolás, y embajador de México en Yugoslavia), ${ }^{35}$ y Thelma Nava del Comité de Solidaridad con el Pueblo de Nicaragua. La organización también contó con la destacada participación de Adolfo Mejía González y Adriana Lombardo Otero, hija del famoso sindicalista mexicano Vicente Lombardo Toledano. ${ }^{36}$ Para este momento ya existían comités estatales en Jalisco, Tamaulipas, Estado de México, Oaxaca y Nuevo León. Tan sólo en la ciudad de México había por lo menos 41 grupos que realizaban acciones de solidaridad.

De acuerdo con informes de la DFs, la "oficina de coordinación" mantenía dos proyectos importantes, recaudar 10000000 de pesos para la compra de armamento pesado, y la recolección de 1000 litros de plasma para ser enviados a Nicaragua (tarea que era coordinada por médicos chilenos exiliados en el país) e incluso se llegó a considerar la integración de brigadas internacionales de mexicanos para combatir junto con el FSLN. ${ }^{37}$

La creación de una coordinadora de solidaridad bajo apoyo directo de la inteligencia cubana y de militantes del FSLN implicaba también la tolerancia o avenencia del Estado mexicano hacia estas actividades, en particular considerando los reportes de la DFS. Esto suponía una diferencia sustancial con el hostigamiento del Estado mexicano pocos años antes. Las actividades del FSLN y la inteligencia cubana en México se realizaban bajo una serie de

${ }^{35}$ Enciclopedia histórica y biográfica de la Universidad de Guadalajara. Recuperada de http:// enciclopedia.udg.mx/biografias/vazquez-pallares-natalio

${ }^{36}$ Sin título. Fondo Gobernación. Dirección Federal de Seguridad. Comité de Solidaridad. Caja 276, f. 172, AGN, México.

${ }^{37}$ Comité de Solidaridad, s. f. Fondo Gobernación. Dirección Federal de Seguridad. Comité de Solidaridad con el pueblo de Nicaragua. Caja 276, leg. 3, f. 146; Sin título. Fondo Gobernación. Dirección Federal de Seguridad. Comité de Solidaridad con el Pueblo de Nicaragua, leg. 2, f. 198. AGN, México. 
"reglas de operación" impuestas por el gobierno mexicano, la principal era la separación total entre los movimientos radicales mexicanos y el movimiento sandinista. De igual forma, la ausencia total de alguna crítica en contra del gobierno priista. ${ }^{38}$

A pesar de estos "acuerdos" para el gobierno de México existía la posibilidad latente de que la lucha en Nicaragua inspirara a los grupos guerrilleros domésticos o que el movimiento de solidaridad radicalizara a los grupos de izquierda en el país, por lo que mantuvo la vigilancia constante al movimiento de solidaridad. Aun así, el gobierno mexicano se mostró cada vez más confiado en que las actividades clandestinas del FSLN se mantendrían dentro de los límites acordados. Como lo indicaba un reporte de la DFs a finales de septiembre de 1978, el subdirector Alfonso Cabrera Morales dio amplias seguridades al embajador de Nicaragua en México, Ernesto Navarro Richards, de que el FSLN y los grupos guerrilleros en México no realizarían un atentado en su contra ya que no había "relación entre el Frente Sandinista y los grupos subversivos en México", además que por las "condiciones políticas de México; [a] ningún nicaragüense le conviene participar en hechos delictivos en México." ${ }^{39}$

El 8 de octubre de 1978 se llevó a cabo un evento en el Auditorio Nacional (el principal recinto artístico del país) que contó con la participación de varios partidos políticos como el PCM, el PST y el PRT, y el partido gubernamental PRI. De acuerdo con informes de la DFS, asistieron alrededor de 5500 personas, agotándose todos boletos del evento. Dentro del auditorio se desplegaron mantas que declaraban "Por un gobierno obrero y campesino en Nicaragua", "Hemos prometido Patria Libre o Morir y lo estamos Cumpliendo" y "La libertad sólo se conquista con las armas, FSLN. Comité de Solidaridad con Nicaragua". La velada contó con la participación de representaciones diplomáticas de los gobiernos de Vietnam, Etiopía, Bolivia, y del gobierno en exilio chileno, el Partido Socialista de Chile, y una representación de Puerto Rico. Durante el concierto, varios grupos interpretaron canciones de protesta mientras el maestro de ceremonias, Pedro Rodríguez, exhortó a los presentes a solidarizarse con los países de América Latina, Argentina, Chile y Nicara-

${ }^{38}$ El FSLN, al igual que los grupos guerrilleros guatemaltecos y salvadoreños o el gobierno cubano no buscaban colaborar con la izquierda armada mexicana o criticar abiertamente al gobierno de México (Joa, 2015; Keller, 2015, p. 234).

${ }^{39}$ Sin título, s. f. Fondo Gobernación. Dirección Federal de Seguridad. Caja 229/4223, exp. 11-56, leg. 5. AGN, México. 
gua. ${ }^{40}$ El permiso del gobierno era necesario para realizar esta y otras actividades por parte del movimiento de solidaridad. ${ }^{41}$

La formación del Comité Coordinador mostró la confluencia de los diversos factores que influían sobre el movimiento de solidaridad en México: las labores de propaganda y organización del FSLN, el apoyo de la inteligencia cubana, la aquiescencia del gobierno mexicano y el entusiasmo popular por la causa nicaragüense. En términos prácticos, la creación del comité organizador le otorgó al gobierno mexicano una mayor vinculación con el movimiento de solidaridad a través de su apoyo informal y su participación en algunas de sus actividades. Thelma Nava, declaró en una entrevista realizada por Emma Yanes que "en galerías y teatros del gobierno se nos dieron todas las facilidades. Con Jesús Reyes Heroles [secretario de Gobernación] tuvimos todo el apoyo; él mismo nos dio dinero de su bolsa" (Yanes Rizo, 2018 p. 84). De acuerdo con documentos de la DFs, una fuente "fidedigna" había informado que el gobierno de México estaba apoyando estas labores por vía de instituciones culturales como la Casa de Cultura del Estado de Chiapas y a través de la Fundación Nacional para Actividades Sociales (FonApAs). ${ }^{42}$ Incluso, el poeta sandinista Francisco de Asís, una de las principales figuras del movimiento de solidaridad, fue director del Departamento de Literatura del Instituto Nacional de Bellas Artes entre 1976 y 1978, mientras era vigilado por la DFs. ${ }^{43}$ Sin embargo, cabría mencionar que no queda claro hasta qué punto las autoridades gubernamentales estaban enteradas de estos apoyos.

El crecimiento del movimiento de solidaridad llevó a un incremento sustancial de la ayuda económica para el FsLN. Para el día 3 de octubre de 1978, el Comité, que también era identificado con el nombre de Comité Coordinador de Fuerza de Paz, informó que hasta la fecha había recabado entre 90000 y 100000 pesos en ayuda para Nicaragua y que contaban con aproxi-

${ }^{40}$ Comité Nacional de apoyo al Frente Sandinista de Liberación Nacional. Fondo Gobernación. Dirección Federal de Seguridad. Comité de Solidaridad con el Pueblo de Nicaragua. Caja 276, leg. 2, f. 144. AGN, México.

${ }^{41}$ Apenas unas semanas antes el gobierno mexicano había decidido enviar a un nuevo encargado de negocios a Nicaragua, Gustavo Iruegas. En palabras del exembajador su misión en Nicaragua era "hacer todo lo que pueda por esa gente y su revolución" (Toussaint, 2013, p. 191).

${ }^{42}$ México-Guatemala-Nicaragua, 19 de octubre de 1978. Fondo Gobernación. Dirección Federal de Seguridad. Comité de Solidaridad con el Pueblo de Nicaragua. Caja 276, leg. 2, f. 205. AGN, México.

${ }^{43}$ Enciclopedia de la literatura en México. Fundación para las Letras Mexicanas. Recuperado de http://www.elem.mx/autor/datos/109913 
madamente 20 cuentas bancarias bajo su control. Posteriormente, a puerta cerrada, se anunció que para el 10 de octubre se habían reunido 174000 pesos que serían enviados directamente al FSLN. ${ }^{44}$ No todo el apoyo recolectado para la lucha en Nicaragua pasaba por la Coordinadora, este era el caso de Méndez Arceo en Cuernavaca. Para dar una muestra de la cantidad de dinero recolectado en México, a finales de octubre de 1978, un dirigente regional del PCM, quien había sido parte de una colecta de fondos entre los sindicatos de la Universidad Autónoma de Puebla declaró que, tan sólo en ese sindicato, se habían recolectado más de 230000 pesos y que estos se habían entregado a un "representante del FSLN" quien lo remitió a Panamá. ${ }^{45}$ No tenemos una suma total del dinero recolectado por la Coordinadora de Solidaridad y otras organizaciones, aunque es posible que ascendiera a varios millones de pesos ya que múltiples sindicatos de gran tamaño como el STUNAM y el SME colaboraron con colectas similares entre sus miembros, por no mencionar los partidos políticos y organizaciones civiles. ${ }^{46}$

A pesar de los avances significativos en la colecta de recursos para el FSLN, los esfuerzos de solidaridad en México fueron importantes debido a su peso político. A finales de 1978 un informe de la DFs señaló que económicamente "la Oficina de Coordinación no está haciendo tan bien como lo esperaban los cubanos", sin embargo, en el campo político, "los funcionarios de la Embajada Cubana están contentos con la respuesta de ayuda dada por la Oficina de Coordinación, especialmente por el hecho que el gobernante Partido Revolucionario Institucional y los partidos de oposición mexicanos están trabajando conjuntamente para proveer ayuda a Nicaragua" ${ }^{47}$ La popularidad del movimiento de solidaridad entre la izquierda mexicana representó un incentivo doméstico para mejorar las relaciones entre el gobierno mexicano y el FSLN, que desde 1977 había comenzado un limitado acercamiento (Vázquez y Campos, 2016, pp. 26-27).

${ }^{44}$ Comité Organizador del Consejo Nacional de Fuerzas de Paz, 10 de octubre de 1978. Fondo Gobernación. Dirección Federal de Seguridad. Comité de Solidaridad con el Pueblo de Nicaragua. Caja 276, leg. 2, f. 150. AgN, México.

${ }^{45}$ Partido Comunista Mexicano, 31 de octubre de 1978. Fondo Gobernación. Dirección Federal de Seguridad. Caja 276, leg. 2, f. 246. AGN, México.

${ }^{46}$ Cabría mencionar que no todo el apoyo recolectado para la lucha en Nicaragua pasó por la Coordinadora como el caso de Méndez Arceo en Cuernavaca y el apoyo directo por parte del gobierno mexicano vía el PRI (Cardenal, 2004, p. 139).

${ }^{47}$ Comité de Solidaridad, s. f. Fondo Gobernación. Dirección Federal de Seguridad. Caja 276, leg. 3, f. 146. AGN, México. 
El movimiento de solidaridad en México también respondió a las necesidades políticas y las coyunturas particulares de la situación en Nicaragua. A principios de 1979 los gobiernos de Venezuela y Panamá habían decidido limitar su apoyo al FSLN debido a la derrota electoral de Acción Democrática en Venezuela y el proceso de ratificación de los tratados de Panamá en el senado estadunidense (Sánchez Nateras, 2019, pp. 270-273). En respuesta el FSLN decidió reforzar sus labores de propaganda intentando diversificar sus aliados internacionales y asilar a la dictadura somocista. El XLV Aniversario por la Muerte de Augusto César fue la ocasión perfecta para reforzar los lazos entre el FSLN y las organizaciones mexicanas, evocando la larga historia de apoyo al sandinismo en México. En febrero de 1979 el poeta y sacerdote, Ernesto Cardenal, inició una gira por México visitando el estado de Jalisco (que mantenía un gran número de grupos de solidaridad alrededor del Comité Regional de Solidaridad con el Pueblo de Nicaragua). En Guadalajara, Cardenal declaró que "en su opinión el pueblo de México es el más Sandinista de América Latina, después de Nicaragua." ${ }^{48}$ Dos días después Cardenal estuvo presente en un acto de solidaridad en el exconvento del Carmen frente a un público de más de 1000 personas, durante el cual hizo hincapié en que uno de los principales dirigentes del FSLN era el mexicano Víctor Tirado López. ${ }^{49}$

Sergio Ramírez, miembro del Grupo de los 12 y del FSLN, también participó en los actos por el XLV Aniversario de la Muerte de Sandino que contó con la participación de los principales partidos de izquierda en el país. ${ }^{50}$ Ramírez también buscó enfatizar los lazos históricos que unían al FSLN con México: "Sandino salió de México para infundir su lucha a los demás hermanos de su pueblo y se fue a las montañas a armar un ejército en contra del imperialismo; detrás de cada nicaragüense debe haber un Mexicano para que tenga menos oportunidad de desistir; el imperialismo morirá en Nicaragua antes de lo que imaginamos." ${ }^{51}$

${ }^{48}$ Estado de Jalisco, 10 de febrero de 1979. Fondo Gobernación. Dirección Federal de Seguridad. Comité de Solidaridad. Caja 276, leg. 2, f. 131. AgN, México.

${ }^{49}$ Estado de Jalisco, 12 de febrero de 1979. Fondo Gobernación. Dirección Federal de Seguridad. Comité de Solidaridad. Caja 276, leg. 3, f. 149. AGn, México.

${ }^{50}$ Aniversario de la muerte del general Augusto César Sandino, 28 de febrero de 1979. Fondo Gobernación. Dirección Federal de Seguridad. Comité de Solidaridad. Caja 276, leg. 3, f. 80. AGN, México.

${ }^{51}$ Aniversario de la muerte del general Augusto César Sandino, 28 de febrero de 1979. Fondo Gobernación. Dirección Federal de Seguridad. Comité de Solidaridad. Caja 276, leg. 3, 
En el marco de estas celebraciones, el 25 de febrero de 1979 se realizó un segundo acto de solidaridad en el Auditorio Nacional ante aproximadamente 3500 personas. Durante el evento Tomás Borge, uno de los principales dirigentes del fSLN, miembro de la Dirección Nacional de la facción GPP, declaró que a los sandinistas "no les extraña la solidaridad que el pueblo de México otorga al [FSLN], pues en otras ocasiones México lo ha hecho también hacia otros pueblos que luchan contra el imperialismo Yanqui". ${ }^{52}$

\section{EL MOVIMIENTO DE SOLIDARIDAD Y LA OPOSICIÓN}

A pesar de que el movimiento de solidaridad reforzó la convergencia de intereses entre las organizaciones políticas de izquierda y el gobierno mexicano, también abrió un foro para expresar críticas en contra de la represión por parte del gobierno y las condiciones antidemocráticas imperantes en México.

El auge del movimiento de solidaridad en septiembre de 1978 coincidió con los preparativos para las conmemoraciones del décimo aniversario de la masacre de Tlatelolco, que fueron constantemente recodados durante los actos de solidaridad por todo el país. En Michoacán, los estudiantes de la Escuela Normal Rural "Vasco de Quiroga" realizaron pintas en Morelia, mostrando las fotografías de Gustavo Díaz Ordaz, Luis Echeverría y José López Portillo y el texto "Ante diez años de demagogia, diez años de lucha revolucionaria 1968-1978", "Nicaragua derrotará a la dictadura fascista de la familia Somoza", "Fuera imperialistas" ${ }^{53}$ En Durango, durante un evento en la Plaza de Armas, grupos de estudiantes socialistas repartieron volantes recordando la masacre de Tlatelolco, anunciando un evento el 2 de octubre para conmemorar "la violenta represión estudiantil". ${ }^{54}$

También en septiembre de 1978, el colectivo de teatro CLETA organizó un acto en el Foro Abierto de la Casa del Lago en el Bosque de Chapultepec, al

f. 81. AGN, México. Otros miembros del Grupo de los 12, como Arturo Miranda y Carlos Gutiérrez, también participaron en estos eventos de solidaridad.

${ }_{52}$ Sin título, s. f. Fondo Gobernación. Dirección Federal de Seguridad. Comité de Solidaridad. Caja 276, leg. 3, f. 92. AGn, México.

${ }^{53}$ Comité de Solidaridad con el Pueblo de Nicaragua. Fondo Gobernación. Serie Dirección Federal de Seguridad. Caja 276, leg. 2, f. 221. AgN, México.

${ }^{54}$ Comité de Solidaridad con el Pueblo de Nicaragua. Fondo Gobernación. Serie Dirección Federal de Seguridad. Caja 276, leg. 2, f. 224. AGN, México. 
que asistieron más de 500 personas. Durante el evento, adornado con mantas que leían "incorpórate a las brigadas de solidaridad con Nicaragua" y "alto a la represión en el Pueblo de Nicaragua". Se habló de la "situación que prevalece en Nicaragua", pero también se trataron varios temas de protesta, como la situación en la Escuela Nacional de Maestros, acusando al gobierno y autoridades educativas de "ineptos". También protestaron por la interferencia de la policía en las instalaciones de la unAm y se convocó a una marcha para conmemorar el aniversario de la masacre estudiantil del 2 de octubre de 1968. En el mismo evento, la Coalición de Mujeres Feministas "manifestó su lucha por tener los mismos derechos que el hombre." ${ }^{55}$

El problema de los desaparecidos en México se convirtió en un tema recurrente en los diversos actos de solidaridad. Por ejemplo, el 19 de noviembre de 1978, en la Casa del Lago, en la Ciudad de México, el Comité Nacional pro-Defensa de Presos, Perseguidos, Desaparecidos y Exiliados Políticos organizó un gran evento de solidaridad con Nicaragua ante la presencia de más de 1000 asistentes. Durante la jornada, en la que participaron varios exiliados "nicaragüenses, uruguayos y chilenos", uno de los miembros del Comité "exigió al Gobierno de México la presentación de 380 desaparecidos” pidiendo apoyo para las huelgas de hambre en las ciudades de Guadalajara, Monterrey, Culiacán, Chilpancingo y Distrito Federal. En los años siguientes, Rosario Ibarra y el Comité Nacional pro-Defensa de Presos, Perseguidos y Desaparecidos se convirtieron en figuras constantes en los actos de solidaridad con El Salvador (Pirker y Nuñez Rodríguez, 2016).

Las acciones de oposición no sólo eran vertidas en contra del gobierno federal, también eran especialmente críticas de los gobiernos locales, los cuales, a pesar del apoyo del gobierno federal al movimiento de solidaridad, se mostraron preocupados por las manifestaciones públicas que agrupaban a grandes sectores de la izquierda nacional. Como indicaba el seguimiento de un multitudinario acto de solidaridad con Nicaragua el 21 de febrero de 1979, Joel Robles Uribe, coordinador del Comité Regional de Solidaridad con el pueblo de Nicaragua de Jalisco: "Agregó que ellos estaban advertidos por las autoridades para no realizar actos públicos como éste, ya que se siente un clima de intranquilidad en esta ciudad." En Michoacán, durante una jornada de solidaridad organizada por diversos partidos de izquierda, Efrén Capiz Vi-

${ }_{55}$ Casa del lago. 24 de septiembre de 1978 Fondo Gobernación, Serie Dirección Federal de Seguridad. FSLN-Comité de Solidaridad (versión pública). Caja 276, leg. 2, f. 47. AGN, México. 
llegas señaló que existían amplios paralelos entre lo que sucedía en Nicaragua y en México: "también en México existe la explotación por unos cuantos". Villegas recordó los hechos registrados en 1968 y 1971 en el Distrito Federal, así como en 1949 y 1963 en Morelia, donde dijo "fueron masacrados cientos de estudiantes que trataron de derrocar al 'gobierno opresor'." 56

En Morelos, donde existía una fuerte organización de izquierda, el movimiento de solidaridad también sirvió para encauzar las luchas locales y para denunciar al gobierno mexicano. A principios de marzo de 1979, durante un acto de solidaridad con Nicaragua, varios militantes del PRT denunciaron el hecho de que en el estado había más de 28 presos políticos y más de 360 desaparecidos a nivel nacional, culpando al "PRI-gobierno", y al "gobierno imperialista de James Carter" por esta situación. Durante el evento, se cantaron varias canciones de protesta "atacando al PRI y al Gobierno Federal", a los cuales señalaron como "títeres de la CIA". ${ }^{77}$

El espectro de un movimiento armado en México también se mantuvo vivo en varios actos de solidaridad, en particular en estados donde se había vivido con gran intensidad la lucha clandestina como Jalisco, Guerrero, o Monterrey. Durante un evento conmemorando el XLV Aniversario de la Muerte de Sandino, un miembro de la Federación de Estudiantes de Guadalajara señaló que "en última instancia", "los comités de apoyo tomarían las armas para continuar la lucha, invitando al pueblo en general a dar su apoyo al movimiento para acabar totalmente al imperialismo." ${ }^{58}$ En el $\mathrm{cCH}$ Vallejo de la Ciudad de México, algunos volantes decían: "Ayer Cuba, hoy Nicaragua, mañana...". ${ }^{59}$

${ }^{56}$ Estado de Michoacán. Fondo Gobernación, Serie Dirección Federal de Seguridad. Comité de Solidaridad. Caja 276, leg. 2, f. 18. AGN, México.

${ }^{57}$ En la catedral de esta ciudad tuvo lugar un festival de solidaridad con el Pueblo de Nicaragua, 9 de marzo de 1979. Fondo Gobernación, Serie Dirección Federal de Seguridad. Comité de Solidaridad con el Pueblo de Nicaragua. Caja 276, leg. 3, f. 153. Agn, México.

${ }^{58}$ Estado de Jalisco, 21 de febrero de 1979. Fondo Gobernación, Serie Dirección Federal de Seguridad. Comité de Solidaridad. Caja 276, leg. 2, f. 218. AGN, México.

59 "FSLN. Apoya a Nicaragua". Volante del Comité de Solidaridad con Nicaragua CCH Vallejo, 1979. Archivo personal de Francisco Navarro. 


\section{LA MÁSCARA DE LA SOLIDARIDAD: EL FSLN Y EL ESTADO MEXICANO}

Durante 1978, el gobierno mexicano mantuvo una política de apoyo velado y hacia las acciones del FSLN en su territorio nacional, aprovechando el entusiasmo provocado por la insurrección sandinista entre la izquierda mexicana. Sin embargo, a principios de 1979 el gobierno mexicano comenzó a modificar su política avanzando hacia un respaldo cada vez más abierto al FSLN, impulsado en gran medida por el deterioro de la situación regional tras el colapso de la mediación estadunidense. ${ }^{60} \mathrm{El}$ objetivo del gobierno mexicano era limitar la influencia de los grupos que consideraba "radicales" sobre el movimiento Sandinista, de forma parecida a su policía hacia la izquierda doméstica (Herrera León, 2011).

Existían importantes limitaciones de la entrega de ayuda directa por parte del gobierno mexicano al FSLN. Durante años el gobierno mexicano había sostenido la doctrina Estrada y la no intervención como el fundamento de su política exterior. Apoyar abiertamente a un grupo guerrillero extranjero significaba romper con esta política (Herrera León, 2011, p. 230). También podía llevar a un conflicto político y diplomático con el gobierno estadunidense. Como señalaba en sus memorias el encargado de negocios de México en Nicaragua, Gustavo Iruegas, algunos sectores del gobierno mexicano se encontraban preocupados por tomar medidas, como la ruptura de relaciones diplomáticas con Nicaragua, que pudiera causar un "problema con los gringos" (Toussaint, 2013, p. 206).

En respuesta a esta peculiar situación, el gobierno decidió utilizar al PRI para canalizar parte de su ayuda hacia el FSLN. Apoyar al Frente por vía del partido le permitió al gobierno mexicano rechazar cualquier acusación de intervencionismo y aminorar la presión estadunidense. De acuerdo con las memorias de Ernesto Cardenal, a principios de marzo el PRI celebró 50 años desde la fundación del partido invitando a varias organizaciones políticas a las celebraciones, entre ellas el fSLN. Algunos representantes del Grupo de los 12 fueron invitados a un banquete en Querétaro, en donde el presidente

${ }^{60}$ La política de México hacia Centroamérica excede los límites de este artículo. Este proceso ha sido explorado desde los años ochenta en varios textos (Herrera, 2011; Toussaint, Vázquez y Castillo, 2011; Vázquez y Campos, 2016; Toussaint, 2016; Sánchez Nateras, 2019, entre otros). 
López Portillo declaró efusivamente “iViva Nicaragua!" al pasar frente a ellos (Cardenal, 2004, p. 139).

Los viajes de solidaridad de importantes figuras del FSLN también sirvieron para afianzar las relaciones entre el gobierno mexicano y el grupo guerrillero. A principios de marzo de 1979, Sergio Ramírez asistió a varias reuniones de coordinación con el movimiento de solidaridad, visitando las oficinas centrales de la Coordinadora de Solidaridad en México junto con otros miembros del Grupo de los 12 . Tras estas reuniones, Ramírez y los Sandinistas se reunieron con Jesús Reyes Heroles, secretario de Gobernación y, posteriormente, con Gustavo Carvajal, presidente del CEN del PRI para afianzar los lazos entre ambos. ${ }^{61}$ A mediados de abril, y tras una serie de importantes discusiones entre funcionarios de la presidencia y la Secretaría de Relaciones Exteriores, se tomó la decisión de romper relaciones diplomáticas con Nicaragua. Decisión que fue coordinada con el FSLN para que tuviera mayor impacto político (Toussaint, 2013, pp. 206-207). Finalmente, México rompió relaciones con Nicaragua el 20 de mayo de 1979.

La ruptura de relaciones fue acompañada de un viaje de solidaridad por parte de una gran comitiva del Grupo de los 12 y el fSLN a México para, en palabras de Ernesto Cardenal, "respaldar la decisión del gobierno de México". Esta comitiva estuvo compuesta por Sergio Ramírez, Joaquín Cuadra Chamorro, Carlos Gutiérrez Sotelo, Carlos Tünnerman, Emilio Baltodano, Casimiro Sotelo, Miguel D’ Escoto, Félix González Hernández y Ernesto Cardenal. Los nicaragüenses fueron recibidos el 25 de mayo por el secretario de Asuntos Internacionales del PRI, Óscar Campero, y alojados en el hotel Reforma. Las declaraciones del Grupo de los 12 ante la prensa fueron halagüeñas hacia el gobierno mexicano. Ernesto Cardenal declaró que "la actitud del Licenciado José López Portillo [...] encarna la conciencia moral de América Latina”, mientras que Emilio Baltodano y Carlos Tünnermann elogiaron la actitud del presidente de México ante el "genocidio" que estaba tomando lugar en Nicaragua. ${ }^{62}$ El 26 de mayo de 1979 tuvo lugar en la ciudad de México una marcha-mitin de solidaridad con Nicaragua que organizó el PRI para apoyar la política del presidente de México en Nicaragua. El evento comenzó en el edificio del

${ }^{61}$ Actividades del doctor Sergio Ramírez Mercado. Nicaragüense del Grupo de los 12, 9 de marzo de 1979. Fondo Gobernación. Serie Dirección Federal de Seguridad. Comité de Solidaridad. Caja 276, leg. 3, f. 122. AGn, México.

${ }^{62}$ Fondo Gobernación. Serie Dirección Federal de Seguridad. Comité de Solidaridad. Arribo de miembros del Grupo de los 12 de Nicaragua, 23 de marzo de 1979. Leg. 3, f. 165. AGN, México. 
PRI y concluyó en la explanada del monumento a la Revolución, y contó con la participación de 23000 asistentes, en su mayoría burócratas del gobierno mexicano. Al evento asistieron los principales dirigentes del PRI a nivel nacional, el presidente del CEN del PRI, el presidente del Sindicato de Trabajadores del Servicio del Estado (FSTE), el secretario general del partido, el secretario general de la Central Nacional Campesina, CNOP, el dirigente del Congreso del Trabajo, además de senadores y diputados de la organización. Como lo señalaba una de las mantas de las organizaciones, el evento era a su vez una muestra de la solidez y poder del PRI y una señal de apoyo al pueblo de Nicaragua: "El pueblo con López Portillo, Apoyamos al pueblo de Nicaragua". ${ }^{63}$

El momento culminante de esta gira fue una serie de reuniones entre los representantes del Grupo de los 12 y varias figuras políticas nacionales. Los miembros del grupo visitaron Los Pinos y se entrevistaron con el presidente mexicano, José López Portillo, a quien agradecieron por "el apoyo que ha brindado al pueblo de Nicaragua" ${ }^{64}$ El día siguiente se reunieron con el secretario de Relaciones Exteriores, Jorge Castañeda, y con el presidente del CEN del PRI, Gustavo Carvajal. Ernesto Cardenal relata que, tras esa reunión, Gustavo Carvajal invitó a los nicaragüenses a una cena donde entregó personalmente al tesorero del grupo 100000 dólares por parte del PRI para poyar la lucha sandinista (Cardenal, 2004, p. 139).

El gobierno de México se valió del PRI y de la simulación de actos de solidaridad como el evento en el monumento a la Revolución para avanzar su política exterior hacia Nicaragua y reforzar una imagen progresiva a nivel doméstico. De acuerdo con telegramas estadunidenses, a finales de junio Gustavo Carvajal declaró ante la prensa que el PRI iniciaría una "cruzada" nacional de apoyo "total" con el pueblo de Nicaragua que incluía donaciones de sangre, ropa, medicinas y apoyo económico al recién anunciado gobierno provisional, enfatizando que esta ayuda no comprometía la política de no intervención del gobierno mexicano, sino que venía del "pueblo de México" a través del PRI. El comentario de la embajada estadunidense simplemente

${ }^{63}$ Partido Revolucionario Institucional, 26 de mayo de 1979. Fondo Gobernación, Serie Dirección Federal de Seguridad. Comité de Solidaridad. Caja 276, leg. 3, f. 108. AgN, México.

${ }^{64}$ Actividades del grupo de los Doce. Frente Sandinista de Liberación Nacional (versión pública), 28 de mayo de 1979. Fondo Gobernación, Serie Dirección Federal de Seguridad. AGN, México. 
señalaba que esta era una "tapadera débil" (por el carácter unificado del PRI y el gobierno mexicano) aunque "técnicamente" correcta. ${ }^{65}$

Durante los últimos dos meses de la insurrección en Nicaragua, el gobierno mexicano fue muy activo en impulsar abiertamente los esfuerzos del ala "moderada" del FSLN para dar legitimidad a un nuevo gobierno provisional. Esto se debía a la preocupación por la inestable situación en Nicaragua, y por el posible aumento de la influencia cubana en la región (Sánchez Nateras, 2019, p. 275). El gobierno mexicano bloqueó los esfuerzos estadunidenses en la Organización de Estados Americanos (OEA) por crear una fuerza de "paz" para intervenir en Nicaragua. De acuerdo con declaraciones de Jorge Luis Joa (2015), el gobierno de México indicó a la inteligencia cubana que podía poner a disposición del FSLN un aeropuerto en Chiapas, en caso de que el puente aéreo entre Cuba y Costa Rica - que proveía de armamento a los sandinistas-, fuera cancelado debido a la presión estadunidense. También, comenzó a enviar armamento en cantidades limitadas al FSLN (Campos, 2016). Tras la victoria revolucionaria, el gobierno mexicano decidió apoyar la conformación de grupos de apoyo para la reconstrucción de Nicaragua movilizando a las estructuras corporativas del PRI, creando Comités Estatales pro-reconstrucción de Nicaragua conformados en su mayoría por miembros del partido. ${ }^{66}$

Durante los siguientes años el Estado mexicano desplegó un gran programa de ayuda para el nuevo gobierno revolucionario, dejando de lado la ficción de la solidaridad. Por su parte, las organizaciones que habían apoyado la lucha con Nicaragua (partidos políticos, sindicatos y colectivos) se mantuvieron activos en su respaldo hacia el gobierno revolucionario; sin embargo, con el recrudecimiento de la crisis política y social en Centroamérica, algunos de estos grupos ampliarían sus esfuerzos de solidaridad para abarcar también la solidaridad con El Salvador y Guatemala (Pirker y Nuñez Rodríguez,

65 "Presidente López Portillo speaks about Nicaragua". Telegrama de la embajada estadunidense en México al Departamento de Estado, 29 de junio de 1979, 1979MEXICO 10901. National Archives and Records Administration (en adelante NARA), USA.

${ }^{66}$ Sin título, s. f. Fondo Gobernación. Dirección General de Investigaciones Políticas y Sociales. Caja 1515C, exp. 12, f. 3. AGN, México. Por ejemplo, el Comité de Sinaloa estaba conformado por un diputado federal del PRI, el presidente estatal del PRI, el dirigente del PARM en el estado, el dirigente estatal del Partido Popular Socialista, el secretario general de la Federación de Organizaciones Populares en Sinaloa, y más de 20 personas de todas la organizaciones y sindicatos cercanos al PRI, desde asociaciones de mujeres (ANFER), agrupaciones juveniles (MJR), sindicatos como el SNTE, grupos campesinos como la FROC, la Unión Regional Ganadera, y el CNOP, así como gente distinguida de la entidad. 
2016). De esta manera, el movimiento de solidaridad con Nicaragua ayudó a afianzar algunas formas de colaboración entre la sociedad mexicana y los grupos armados de aquellos países que tuvieron una gran influencia durante el conflicto Centroamericano.

\section{CONCLUSIÓN}

Entre 1977 y 1979, el movimiento mexicano de solidaridad con Nicaragua se transformó de un pequeño esfuerzo organizado por los grupos de exiliados nicaragüenses y algunos intelectuales mexicanos, en un movimiento social que abarcó todo el país y que contó con el respaldo del Estado mexicano.

A diferencia de las organizaciones de solidaridad en Europa y Estados Unidos, el movimiento de solidaridad en México fue heredero de una larga tradición que se remontaba directamente a los esfuerzos de Augusto César Sandino en México. El proceso de solidaridad continuó durante las siguientes dos décadas mediante las actividades de la comunidad de exiliados nicaragüenses. Durante los años sesenta y setenta, bajo el influjo de la revolución cubana y la guerra fría, el movimiento de solidaridad se transformó, apoyando la creación de organizaciones guerrilleras, bajo la constante vigilancia del Estado mexicano. Estos esfuerzos confluyeron en 1974 con la creación del primer Comité Mexicano de Solidaridad con el Pueblo de Nicaragua, y finalmente en 1977 con el inicio de la insurrección sandinista.

A partir de 1977 el movimiento de solidaridad en México coincidió con un momento de auge de la militancia partidista y sindical propiciado por la reforma política impulsada por el gobierno mexicano. En este contexto, de limitada apertura democrática, la izquierda mexicana retomó el esfuerzo del FSLN y lo adecuó a sus necesidades políticas inmediatas de militancia pública e internacionalismo socialista. Esta peculiar situación fue aprovechada por una comunidad de exiliados nicaragüenses y militantes del FSLN cada vez más activa y numerosa, así como por elementos de la inteligencia cubana.

En este contexto, los intereses del Estado mexicano coincidieron con los del movimiento de solidaridad, el cual apoyó de forma indirecta para avanzar su política exterior y mejorar su posición frente a la oposición doméstica (Aguayo, 1985; Herrera León, 2011). Con el tiempo, el gobierno mexicano se valió de la ficción de la solidaridad PRI-FSLN para avanzar la política exterior del gobierno y mantener una semblanza de no intervencionismo en 
Nicaragua. Sin embargo, como ha sido visto, el movimiento de solidaridad operó bajo la mirada vigilante de los servicios de inteligencia del Estado y, en algunos casos, bajo el hostigamiento de los gobiernos locales, mostrando hasta cierto punto la sospecha del Estado frente a estas formas de organización y participación política.

La popularidad del movimiento de solidaridad también permitió que este fuera utilizado para dar cauce a la protesta social y la inconformidad con la situación en el país. Las críticas por los asesinatos de estudiantes en 1968 y 1971; los abusos de las fuerzas del Estado; los reclamos ante los cientos de desapariciones forzadas fueron constantes durante los conciertos, mítines y protestas a favor de la lucha en Nicaragua. Varios movimientos sociales lograron presentar sus demandas y mostrar las similitudes entre el régimen antidemocrático en México y Nicaragua al amparo de la solidaridad con el pueblo de Nicaragua.

El movimiento de solidaridad tuvo tres ejes: el FSLN, la izquierda nacional y el gobierno mexicano. Estos tres actores buscaron de diversas formas utilizar el movimiento de solidaridad para avanzar en sus objetivos políticos. Para el Estado mexicano la solidaridad con Nicaragua permitió fortalecer su política exterior y mejorar su posición frente a los grupos de izquierda en el país. Para los grupos de solidaridad, la ayuda para la revolución representó una oportunidad de proyección política, y en términos generales, un paso adelante para todas las luchas de liberación a nivel global, incluida la mexicana. El fSLN, a su vez, logró interactuar con ambos actores, y aprovechar esta peculiar coyuntura política en México para avanzar su proyecto revolucionario.

\section{LISTA DE REFERENCIAS}

Aguayo Quezada, S. (1985). La seguridad nacional y la soberanía mexicana entre Estados Unidos y América Central. En M. Ojeda (ed.), Las relaciones de México con los países de América Central (pp. 43-74). México: El Colegio de México.

Agreda Portero, J. M. y Helm, C. (2016). Solidaridad con la revolución sandinista. Comparativa de redes transnacionales: los casos de la República Federal de Alemania y España. Naveg@mérica. Revista Electrónica Editada por la Asociación Española de Americanistas, 17. Recuperado de https://revistas.um.es/navegamerica/ article/view/271921 
Altamirano, B. (2000). De Raudales a la fundación del Frente. En M. Baltodano, Memorias de la lucha Sandinista. Recuperado de https://memoriasdelaluchasandinista.org/view_stories.php?id=7

Apelt, F. (2015). Between solidarity and emancipation? Female solidarity and Nicaraguan Revolutionary Feminism. En J. Hansen y C. Helm, Making sense of the Americas. How protest related to America in the 1980 s and beyond. Chicago: University of Chicago Press.

Brigham, R. K. (1998). Guerrilla diplomacy. The NLF foreign relations and the Vietnam war. Londres: Cornell University Press.

Campos, F. (2012). La diplomacia sandinista y el triunfo de la revolución popular en Nicaragua, 1976-1979. (Tesis de maestría). Universidad Nacional Autónoma de México, México.

Campos, F. (2016). La Dirección Federal de Seguridad y los revolucionarios guatemaltecos, 1947-1985. En M. Vázquez y F. Campos, México ante el conflicto centroamericano. Testimonio de una época. México: Bonilla Artigas.

Cardenal, E. (2004). La revolución perdida. Madrid: Trotta.

Carr, B. (2014). Pioneering transnational solidarity in the Americas: The movement in support of Augusto C. Sandino 1927-1934. Journal of Iberian and Latin American Research, 20(2), 141-152. DoI: https://doi.org/10.1080/13260219.2014.939122

Christiaens, K. (2014). Between diplomacy and solidarity. Western European support networks for Sandinista Nicaragua. European Review of History: Revue Européenne d'Histoire, 21(4), 617-634. DoI: https://doi.org/10.1080/13507486.2014.933184

Christiaens, K. (2018). European reconfigurations of transnational activism: Solidarity and human rights campaigns on behalf of Chile during the 1970s and 1980s. International Review of Social History, 63(3), 413-448. DoI: https://doi.org/10.1017/ S0020859018000330

Connelly, M. (2002). A diplomatic revolution: Algeria's fight for independence and the origins of the post-cold war era. Nueva York: Oxford University Press.

Fernández, N. (1978). La reforma política: orígenes y limitaciones. Cuadernos Políticos, 16, 16-30. Recuperado de http://www.cuadernospoliticos.unam.mx/cuadernos/ num16.html

Fernández Hellmund, P. (2013). ¡Q Quiten las manos de Nicaragua! Solidaridad argentina con la revolución Sandinista (1979-1990). Sí Somos Americanos. Revista de Estudios Trasfronterizos, 13(2). DoI: http://dx.doi.org/10.4067/S0719-09482013000200003

Gaxiola Lazcano, A. V. (2018). La reforma política de 1977: una democracia con falla de origen. En J. Cadena Roa, M. Aguilar Robledo y D. E. Vázquez Salguero (coords.), Las ciencias sociales y la agenda nacional. Reflexiones y propuestas desde las 
ciencias sociales. México: Universidad Autónoma de San Luis Potosí/El Colegio de San Luis/ConAcyT.

Hatzky, C. y Stites Mor, J. (2014). Latin American transnational solidarities: Contexts and critical research paradigms. Journal of Iberian and Latin American Research, 20(2), 127-140. DoI: https://doi.org/10.1080/13260219.2014.939121

Herrera León, F. (2011). El apoyo de México al triunfo de la revolución sandinista: su interés y uso políticos. Anuario Colombiano de Historia Social y de la Cultura, 38(1), 219-240. Recuperado de https://revistas.unal.edu.co/index.php/achsc/article/ view/23186

Jeifets, V. y Jeifets, L. (2017). La Comintern, el PCM y el "Caso Sandino": una historia de una alianza fracasada 1927-1930. Anuario Colombiano de Historia Social y de la Cultura, 44(2), 63-86. DoI: https://doi.org/10.15446/achsc.v44n2.64015

Joa, J. L. (2015). Cuando triunfó la revolución pensaba ser piloto de guerra y terminé siendo un internacionalista. En L. Suárez Salazar y D. Kruijt, La revolución cubana en nuestra América: el internacionalismo anónimo. Panamá: Ruth Casa Editorial.

Keller, R. (2015). Mexico's cold war. Cuba, the United States, and the legacy of the Mexican revolution. Nueva York: Cambridge University Press.

Marchesi, A. (2017). Latin America's radical left: Rebellion and cold war in the global 1960s. Nueva York: Cambridge University Press.

Moreno, L. (2015). Exilio nicaragüense en México (1937-1947). México: Universidad Nacional Autónoma de México.

Morales Flores, M. (2016). Fotografía de prensa y movimientos armados. Pedro Valtierra en Nicaragua. En M. Vázquez y F. Campos (coords.), México ante el conflicto centroamericano. Testimonio de una época. México: Bonilla Artigas.

Ojeda, M. (1985). Las relaciones de México con los países de América Central. México: El Colegio de México.

Ortega, H. (2004). La epopeya de la insurrección. Managua: Lea Grupo editorial.

Pérez, J. (2020). Entre la solidaridad, el abuso y el conflicto: la vida en los campamentos de refugiados guatemaltecos en Chiapas, 1981-1998. (Tesis de Doctorado). El Colegio de México, México.

Perla, H. (2009). Heirs of Sandino. The Nicaraguan revolution and the U.S.-Nicaraguan Solidarity Movement. Latin American Perspectives, 36(6), 80-100. DoI: https://doi.org/10.1177/0094582X09350765

Picado Lagos, J. (2013). Los amigos venían del sur. San José: UNED.

Pirker, K. y Núñez Rodríguez, O. (2016). La revolución salvadoreña necesita de la solidaridad del pueblo mexicano. Exilio salvadoreño y activismo político en la 
Ciudad de México. En M. Vázquez y F. Campos (coords.), México ante el conflicto centroamericano. Testimonio de una época. México: Bonilla Artigas.

Rodríguez Kuri, A. y González Mello, R. (2008). El fracaso del éxito (1970-1985). Historia General de México. México: El Colegio de México.

Sánchez Nateras, G. (2019). La última revolución. La insurrección sandinista y la guerra fría interamericana. (Tesis de Doctorado). El Colegio de México, México.

Toussaint, M. (2013). Diplomacia en tiempos de guerra. Memorias del Embajador Gustavo Iruegas. México: Instituto Mora/CIALC/La Jornada.

Toussaint, M. (2016). ¿Activismo o intervencionismo? México frente a Nicaragua, 19778-1982. En M. Vázquez y F. Campos (coords.), México ante el conflicto centroamericano. Testimonio de una época. México: Bonilla Artigas.

Toussaint, M., Rodríguez de Ita, G. y Vázquez, M. (2001). Vecindad y diplomacia: Centroamérica en la política exterior mexicana, 1821-1988. México: Acervo Histórico Diplomático-Secretaría de Relaciones Exteriores.

Toussaint, M., Vázquez, M., Castillo, M. Á. (2011). Historia de las relaciones internacionales de México, 1821-2010. Vol. 2. Centroamérica. México: Secretaría de Relaciones Exteriores.

Valdez Gordillo, M. E. (2016). La región de frontera, de zona de conflicto, selvas y alzamientos a retaguardia estratégica de la URNG: entre la defensa territorial y el apoyo a la guerrilla. En M. Vázquez y F. Campos, México ante el conflicto centroamericano. Testimonio de una época: México: Bonilla Artigas.

Van Ommen, E. (2016). La revolución sandinista en los Países Bajos: los comités de solidaridad holandeses y Nicaragua (1977-1990). Naveg@mérica. Revista Electrónica Editada por la Asociación Española de Americanistas, 17. Recuperado de https://revistas.um.es/navegamerica/article/view/271861

Van Ommen, E. (2020). Isolating Nicaragua's Somoza: Sandinista diplomacy in western Europe, 1977-1979. En T. Field, S. Krepp y V. Pettinà (eds.), Latin America and the global cold war (pp. 367-393). Chapel Hill: University of North Carolina Press.

Vázquez, M. y Campos, F. (coords.) (2016). México ante el conflicto centroamericano. Testimonio de una época. México: Bonilla Artigas.

Vázquez, M. y Campos, F. (2019). Solidaridad transnacional y conspiración revolucionaria. Cuba, México y el Ejército Guerrillero de los Pobres de Guatemala, 19671976. Estudios Interdisciplinarios de América Latina y el Caribe, 30(1), 72-95. Recuperado de http://www3.tau.ac.il/ojs/index.php/eial/article/view/1598

Yanez Rizo, E. (2018). Araceli. ¡La libertad de vivir! México: Fondo de Cultura Económica. 
Yankelevich, P. (2019). Los rostros de Jano: vigilancia y control de los exiliados latinoamericanos en México (1960-1980). Estudios Interdisciplinarios de América Latina y el Caribe, 30(1). Recuperado de http://www3.tau.ac.il/ojs/index.php/eial/article/ view $/ 1600$

\section{OTRAS FUENTES}

Archivos

AGN Archivo General de la Nación, México.

AIHNC Archivo del Instituto de Historia Nicaragua y Centroamérica, Nicaragua.

CIA Central Intelligence Agency Archive-fora Collection, Estados Unidos.

NARA National Archives and Records Administration, Estados Unidos.

Archivo personal de Francisco Navarro, México

Archivos de la Represión, México, en https://archivosdelarepresion.org 